\title{
Uncoupling of EphA/ephrinA Signaling and Spontaneous Activity in Neural Circuit Wiring
}

\author{
Isabel Benjumeda, ${ }^{1 \star}$ Augusto Escalante, ${ }^{1 \star}$ Chris Law, ${ }^{2 \star}$ Daniel Morales, ${ }^{2,3}$ Geraud Chauvin, ${ }^{1}$ Gerald Muça, ${ }^{1}$ Yaiza Coca, ${ }^{1}$ \\ Joaquín Márquez, ${ }^{1}$ Guillermina López-Bendito, ${ }^{1}$ Artur Kania,,${ }^{2,3,4,5}$ Luis Martínez, ${ }^{1}$ and Eloísa Herrera ${ }^{1}$ \\ ${ }^{1}$ Instituto de Neurociencias, Consejo Superior de Investigaciones Científicas and Universidad Miguel Hernández, Campus San Juan de Alicante, 03550 \\ Alicante, Spain, ${ }^{2}$ Institut de Recherches Cliniques de Montréal, Montréal, Québec H2W 1R7, Canada, ${ }^{3}$ McGill University Integrated Program in \\ Neuroscience, Montréal, Québec H3A 2B4, ${ }^{4}$ Departments of Anatomy and Cell Biology, and Biology, Division of Experimental Medicine, McGill University, \\ Montréal, Québec H3A 2B2, and 5Faculté de Médecine, Université de Montréal, Montréal, Québec H3C 3J7, Canada
}

Classic studies have proposed that genetically encoded programs and spontaneous activity play complementary but independent roles in the development of neural circuits. Recent evidence, however, suggests that these two mechanisms could interact extensively, with spontaneous activity affecting the expression and function of guidance molecules at early developmental stages. Here, using the developing chick spinal cord and the mouse visual system to ectopically express the inwardly rectifying potassium channel Kir2.1 in individual embryonic neurons, we demonstrate that cell-intrinsic blockade of spontaneous activity in vivo does not affect neuronal identity specification, axon pathfinding, or EphA/ephrinA signaling during the development of topographic maps. However, intrinsic spontaneous activity is critical for axon branching and pruning once axonal growth cones reach their correct topographic position in the target tissues. Our experiments argue for the dissociation of spontaneous activity from hard-wired developmental programs in early phases of neural circuit formation.

\section{Introduction}

The formation and refinement of vertebrate neural circuits involve neural identity specification, axon targeting, and synaptogenesis, processes that are primarily controlled by hard-wired developmental programs. However, developing neurons exhibit spontaneous electrical activity (Spitzer, 2006), and the extent of its influence over genetically encoded developmental mechanisms is currently under debate.

The classical view posits that activity-independent and activity-dependent programs sequentially regulate different aspects of neural development (Katz and Shatz, 1996; Erzurumlu and Kind, 2001). However, recent evidence suggests

Received April 29, 2013; revised Sept. 22, 2013; accepted 0ct. 7, 2013.

Author contributions: A.K. and E.H. designed research; I.B., A.E., C.L., D.M., G.C., G.M., and Y.C. performed research; G.L.-B. contributed unpublished reagents/analytic tools; J.M., L.M., and E.H. analyzed data; A.K., L.M., and E.H. wrote the paper.

This work was supported by grants from the Regional Government (Promete0 2012-005) and the Spanish Government (BFU2010-16563) to E.H. (BFU2007-67834 and BFU2010-22220) to L.M., and from the European Research Council (ERC-2011-StG 20101109) to E.H. and (ERC-2009-StG 20081210) G.L.-B., I.B. and G.C. are ConsoliderIngenio fellows (CDS2007-023). A.K. is supported by the Canadian Institutes of Health Research (Operating Grant MOP-77556) and the Natural Sciences and Engineering Research Council of Canada. D.M. holds a Mexican Council for Science and Technology (Conacyt) graduate scholarship. We thank A. Barco for critical reading of the manuscript; $G$. Exposito for helping with two-photon microscopy; M. Liang for technical assistance; and R.V. Da Silva for critical comments. We also thank $C$. Varela for help with calcium imaging experiments and retinal extraction surgery.

*I.B., A.E., and C.L. contributed equally to this work.

Correspondence should be addressed to any of the following: Artur Kania, Institut de Recherches Cliniques de Montréal, 110, Avenue des Pins Ouest, Montréal, QC H2W 1R7, Canada, E-mail: artur.kania@ircm.qc.ca; or Luis Martínez or Eloísa Herrera, Instituto de Neurociencias, Consejo Superior de Investigaciones Científicas \& Universidad Miguel Hernández, Campus San Juan de Alicante, Avenida Ramón y Cajal, 03550 Alicante, Spain, E-mail: I.martinez@umh.es or e.herrera@umh.es.

DOI:10.1523/JNEUROSCI.1931-13.2013

Copyright $\odot 2013$ the authors $\quad 0270-6474 / 13 / 3318208-11 \$ 15.00 / 0$ that spontaneous activity may be more of a critical player at earlier developmental stages than previously thought, influencing the expression and function of transcription factors and axon guidance molecules as well as affecting the concentration of axon guidance receptor secondary messengers such as calcium or cAMP (Nishiyama et al., 2003; Hanson and Landmesser, 2004; Nicol et al., 2007). The representative experiments that raised this idea examined the impact of spontaneous activity on the repulsive signaling mediated by the tyrosine kinase receptor EphA and its ephrinA ligand in both the developing chick spinal motor neurons and the mammalian visual system. Limb-innervating motor neurons of the spinal lateral motor column (LMC) are segregated into dorsal limb muscle-innervating lateral LMC motor neurons and ventral limb muscle-innervating medial LMC motor neurons. The binary decision of motor axon projection to the ventral or to the dorsal limb mesenchyme is mediated, at least in part, by the repulsive signaling from ephrins expressed in the limb to axonally expressed EphA4 receptors (Kao et al., 2012). These motor neurons are electrically active even before they form synapses with their target muscles (O'Donovan and Landmesser, 1987), and it has been proposed that this spontaneous activity may influence their guidance by modulating the expression and/or function of axon guidance receptors such as EphA4 (Hanson and Landmesser, 2004). In the visual system, the classical view proposes that EphA/ephrinA signaling and spontaneous activity in the form of retinal waves act independently and sequentially to form the retinotopic map in the visual targets (McLaughlin et al., 2003; Pfeiffenberger et al., 2006; Cang et al., 2008). However, a set of in vitro experiments 
challenges this view and suggests that early spontaneous activity might be essential for the action of EphA/ephrinA signaling (Nicol et al., 2007).

In the last few years, these and other results have stirred the debate on the influence of spontaneous activity in early stages of development, particularly its effects on EphA/ephrinA-mediated signaling. Here, we analyze in vivo the contribution of spontaneous activity in early (neural specification and pathfinding) and late (topography and axonal refinement) phases of development in two topographically organized systems, the chick spinal motor neurons and the mouse visual system. Our results show that ectopic expression of EphA is sufficient to change axon trajectories and mapping, even in the absence of neural activity, and that activity is, in turn, needed for local axon branching and pruning. These results demonstrate that, in the developing motor and visual systems, EphA/ephrinA signaling and neural activity interact in a very limited manner.

\section{Materials and Methods}

Animals. ICR female mice obtained from a timed pregnancy-breeding colony at the Instituto de Neurociencias (IN) were used in all the visual system experiments. E0 was defined as midnight before a plug was found. Animal protocols were approved by the IN Animal Care and Use Committee and National and European laws. Fertilized chick eggs (Couvoir Simetin) were stored for a maximum of 1 week at $18^{\circ} \mathrm{C}$, then incubated at $38^{\circ} \mathrm{C}$ and staged according to standard protocols (Hamburger and Hamilton, 1992).

In ovo electroporation. Chick spinal cord electroporation of expression plasmids was performed at Hamburger and Hamilton stage (HH st.) $18 / 19$, generally as described previously (Kao et al., 2012). In brief, a 5 $\mu \mathrm{g} / \mu \mathrm{l}$ solution of plasmid DNA in distilled water was injected into the lumbar neural tube through a small eggshell window under a Discovery V12 stereomicroscope (Zeiss). Lower bodies of chick embryos were then electroporated with platinum/iridium electrodes (FHC) and the TSS20 Ovodyne electroporator (Intracel; settings: $30 \mathrm{~V}, 5$ pulses $50 \mathrm{~ms}$ wide in a $1 \mathrm{~s}$ interval). Shell windows were sealed with Parafilm (Pechiney Plastic Packaging Company) and incubated at $37^{\circ} \mathrm{C}$ until harvesting at $\mathrm{HH}$ st. $29 / 30$. The efficiency of electroporation varied between 5 and $30 \%$ of total LMC neurons electroporated, depending on the construct and DNA concentration used.

HRP retrograde labeling of motor neurons. Retrograde labeling of chick motor neurons $(\mathrm{MN})$ was performed as described previously (Luria et al., 2008). In brief, chick HH st. 29/30 embryos were harvested and incubated in Tyrode's solution ( $140 \mathrm{~mm} \mathrm{NaCl}, 3 \mathrm{~mm} \mathrm{KCl}, 17 \mathrm{~mm} \mathrm{NaHCO}, 12$ mu glucose, $2 \mathrm{~mm} \mathrm{CaCl}_{2}, 1 \mathrm{~mm} \mathrm{MgCl}_{2}$; Fisher Scientific) at room temperature, and were aerated with $95 \%$ oxygen and $5 \% \mathrm{CO}_{2}$. The retrograde tracer used was a $20 \%$ solution of HRP (Roche) made by dissolving $100 \mathrm{mg}$ of HRP in $450 \mu \mathrm{l}$ of PBS (137 mM NaCl, $2.7 \mathrm{~mm} \mathrm{KCl}, 4.3 \mathrm{~mm}$ $\mathrm{Na}_{2} \mathrm{HPO}_{4}, 1.47 \mathrm{~mm} \mathrm{KH}_{2} \mathrm{PO}_{4}$ ) with $50 \mu$ of $10 \%$ lysophosphatidylcholine (Fluka) in PBS. The HRP solution was injected into either dorsal or ventral hindlimb shank musculature of chick embryos; embryos were incubated in oxygenated Tyrode's solution at $30^{\circ} \mathrm{C}$ for $5 \mathrm{~h}$ before fixation.

Immunostaining. Sectioned tissue was first washed in PBS, incubated in blocking solution ( $1 \%$ heat-inactivated horse serum in $0.1 \%$ TritonX/PBS; Sigma) for $5 \mathrm{~min}$, followed by incubation overnight at $4^{\circ} \mathrm{C}$ in selected primary antibodies diluted in blocking solution. The following primary antibodies were used: mouse anti-Isl1 (1:100; Tsuchida et al., 1994); mouse anti-Lim1/2 (1:100; Tsuchida et al., 1994); goat anti-HRP (1:2000; Jackson ImmunoResearch Laboratory); rabbit anti-EphA4 (1: 500; Santa Cruz Biotechnology); guinea-pig Foxp1 (1:1000; gift from Dr. Bennett Novitch, UCLA, Los Angeles, CA); and mouse antineurofilament (1:100; DSHB). After incubation in primary antibodies, samples were washed with PBS and incubated with appropriate secondary antibodies for $1 \mathrm{~h}$ at room temperature. Secondary antibodies manufactured by either Jackson ImmunoResearch (CY5) or Invitrogen (Alexa Fluor 488 and Alexa Fluor 568) against appropriate species were used at 1:500. The protocol for tissue clearing described in Kuwajima et al. (2013) was followed to acquire images from wholemount limbs of chick embryos containing EGFP or Kir2.1/EGFP-expressing axons.

Image acquisition, quantification, and statistical analysis of motor neuron data. Images were acquired using either a Zeiss LSM 700 or LSM 710 confocal microscope with Zen imaging software (Zeiss). For analysis of EphA4 expression levels, a region of interest that covered $\operatorname{Lim} 1^{+}$, Foxp $1^{+}$, and Kir2.1/EGFP ${ }^{+}$neurons was drawn. This drawn region was fit into the $\operatorname{Lim} 1^{+}, \mathrm{Foxp}^{+}$region of the unelectroporated side. The mean pixel intensity of the electroporated and unelectroporated sides of the spinal cord was then calculated using ImageJ (NIH Image), and a ratio of these two values was quantified per section. Similar methods were used to quantify EphA4 levels in axons, but the region of interest was defined by neurofilament staining of the spinal ventral root. To assay misprojections, motor neurons that were $\mathrm{GFP}^{+}, \mathrm{HRP}^{+}$, and either $\mathrm{Lim}^{+}{ }^{+}$or Isl $1^{+}$were quantified by combining cell counts of a series of spinal cord section images (5-30 $12 \mu \mathrm{m}$ sections from each embryo) using Photoshop (Adobe). Data from the experimental replicate sets were evaluated using Prism. Means of the combined proportions or cell numbers were compared with two-tailed, unpaired Student's $t$ tests with the threshold for statistical significance set at 0.05 .

Ex vivo calcium imaging in chick spinal cord. Chick embryos were coelectroporated with either G-GECO and Kir2.1/mCherry under control of the CMV promoter or R-GECO, and either EGFP, under the control of the $\mathrm{Hb} 9$ promoter-enhancer, or Kir2.1/EGFP, under the control of the CAG promoter, at a ratio of 1:5, as described above, then incubated until HH St. 29/30. Lumbar spinal cords were then dissected and placed ventral side down into an imaging chamber with circulating oxygenated Tyrode's solution (described above) held at $30^{\circ} \mathrm{C}$. Spinal cords were imaged at $1 \mathrm{~Hz}$ for $10 \mathrm{~min}$ using a Zeiss inverted microscope with a Yokogawa spinning disk confocal system installed. Calcium activity was assessed using Image (NIH) and a custom MATLAB (Mathworks) algorithm that looks for large changes in calcium indicator fluorescent intensity, defined here as "events."

DNA plasmids, in utero electroporation, immunohistochemistry, and $q R T-P C R$ in the retina. The coding sequences of human Kir2.1 and mouse EphA6 were cloned in a plasmid to drive their expression under the potent general CAG promoter. All the in utero electroporation experiments were performed by coelectroporating CAG-EGFP and CAGKir2.1iresEGFP (Kir2.1/EGFP) as described by Garcia-Frigola et al. (2007), except those in Figure 5 in which the concentrations were 0.2 and $0.5 \mu \mathrm{g} / \mu \mathrm{l}$, respectively, for CAG-EGFP and Kir2.1/EGFP. Mice were perfused with $4 \%$ paraformaldehyde in PBS. Cuts were made in the retina to maintain orientation before wholemounting. Vibratome sections $(80$ $\mu \mathrm{m})$ from the SC of electroporated mice were washed in PBS- $0.1 \%$ Triton $\mathrm{X}-100$ (PBT) and incubated for $2 \mathrm{~h}$ at room temperature with $1 \%$ BSA-PBT and $10 \%$ horse serum. Sections were then inmunostained with rabbit anti-GFP (1:2000; Abcam) and mounted serially. Retinas and sections were photographed using a TCS SP2 AOBS Laser Scanning Confocal Microscope (Leica Microsystems). qRT-PCR for EphA6 and EphA5 was performed using protocol and primers as previously described (Carreres et al., 2011). To specifically detect the human Kir2.1 introduced by in utero electroporation, the following primers were used to perform qRT-PCR: forward, AACCAACCGCTACAGCATCGT; reverse, TTCT TCACAAAGCGGCTCCTG. Anti-Kir2.1 antiserum (Abcam; 1:800) was used to confirm protein expression.

Ex vivo calcium imaging in the retina. Retinas from embryos coelectroporated with CAG-DsRed and CAG-Kir2.1 plasmids were bulk loaded with the calcium indicator Fluo4 (Invitrogen) using a variant of the multicell bolus loading technique (Stosiek et al., 2003). Fluo4 solution was injected into the vitreous chamber with a micropipette in anesthetized mice. Up to four injections were applied to each animal. Mice were placed on a warm surface at $37^{\circ} \mathrm{C}$ for up to $3 \mathrm{~h}$ and anesthetized for decapitation and retina extraction. Retinas were placed in Ringer's solution containing $135 \mathrm{~mm} \mathrm{NaCl}, 5 \mathrm{~mm} \mathrm{KCL}, 2 \mathrm{~mm} \mathrm{CaCl} 2,1 \mathrm{~mm} \mathrm{MgCl} 2,10$ mM HEPES, and $10 \mathrm{~mm}$ glucose, and then mounted with the RGC layer facing upward on a cellulose nitrate membrane while applying a vacuum to have direct access to the RGC layer. Epifluorescent calcium imaging was performed on a DM LFSA microscope (Spectra-Physics; KMC 100 immersion cooler, Neslab) using a $10 \times$ or $20 \times$ water-immersion objec- 
A

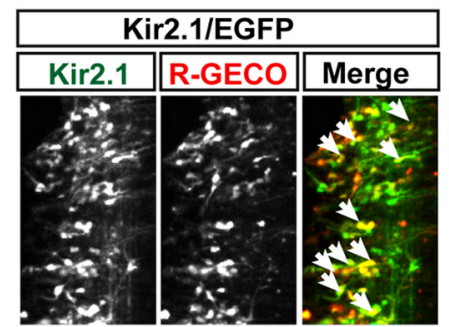

B
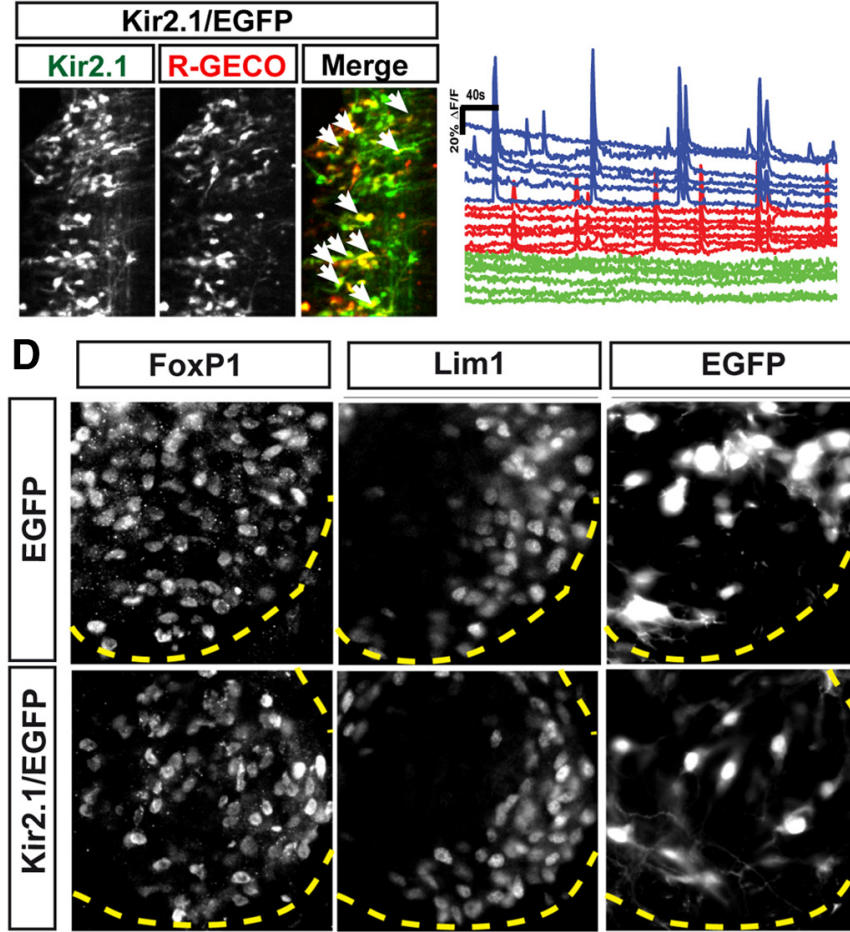

$\mathbf{E}$

Molecular identity of electroporated LMC neurons
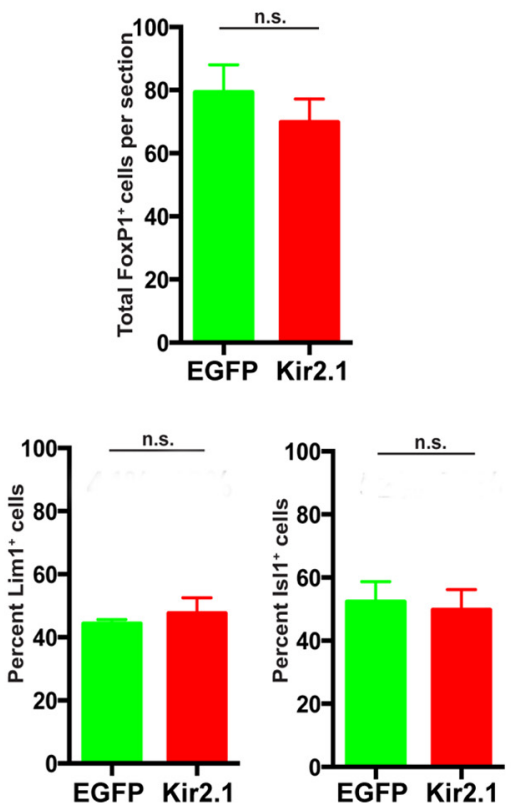

C
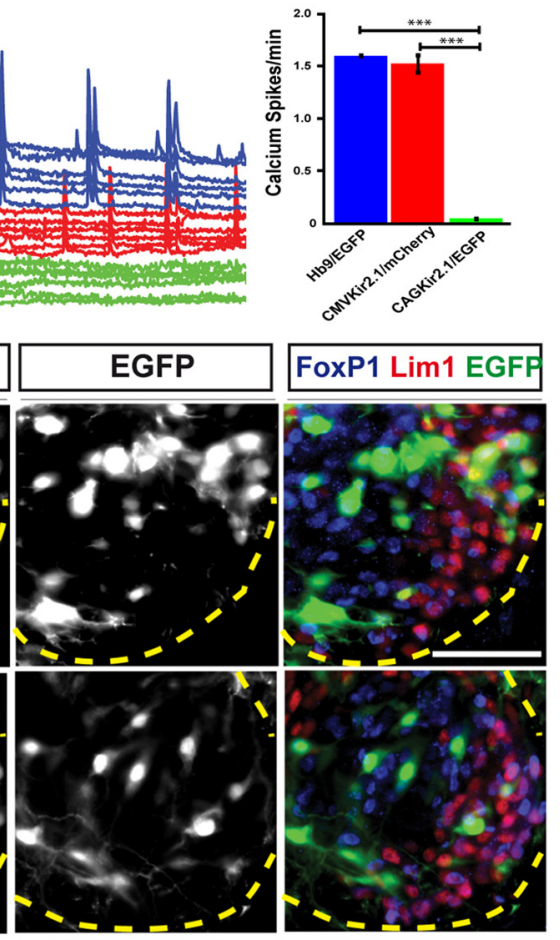

$\mathbf{F}$
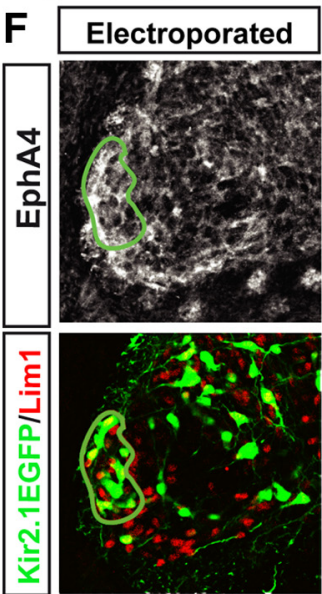

G
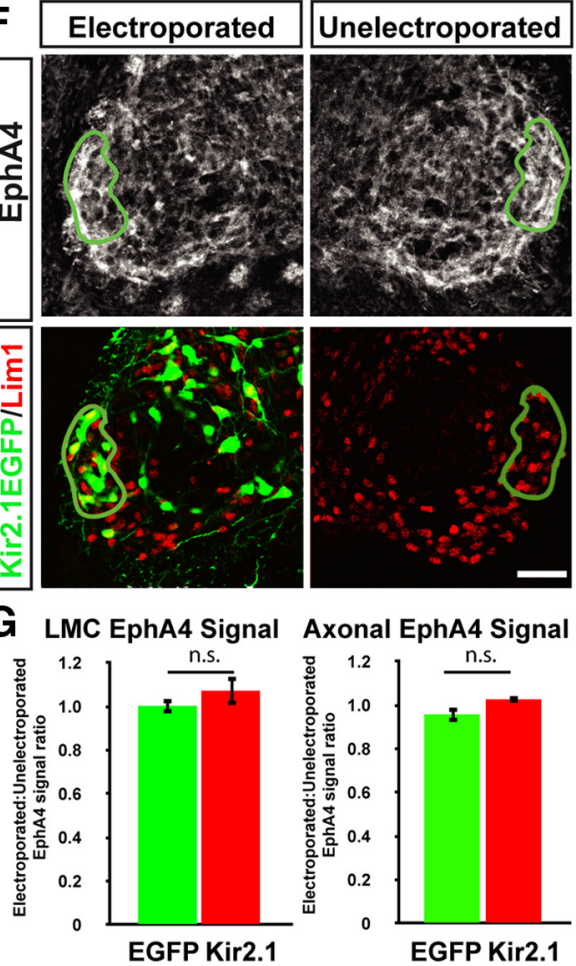

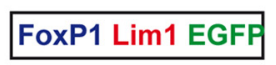

tive with illumination provided by a Leica TCS resonant scanner. Calcium transients were identified in $3 \mathrm{~min}$ epochs, using a custom MATLAB (MathWorks) algorithm, which looks for large changes in calcium indicator fluorescent intensity, defined here as events.

Analysis of targeted axons in the optic chiasm and in the SC. To quantify the number of CAGEGFP- or CAG-Kir2.1/EGFP-expressing axons at the optic chiasm region, square bins were superimposed on the width of the labeled optic nerve proximal to the chiasm and on the contralateral optic tract. Fluorescence intensity within the bin covering the optic nerve [optic nerve fluorescence intensity (ONFI)] and the optic tract contralateral to the electroporated side [optic tract fluorescence intensity (OTFI)] was measured using ImageJ software and standard methods described by Herrera et al. (2003). These two fluorescence measures were normalized to the fluorescence intensity in the corresponding electroporated retina [retinal fluorescence intensity (RFI)]: ONFI/RFI and OTFI/RFI.

To quantify the number of CAG-EGFP- or CAG-Kir2.1/EGFP-expressing axons in the SC of postnatal day $0(\mathrm{P} 0)$ mice, circular bins were superimposed over the entire SC area. Fluores-

section in embryos electroporated with EGFP and $70 \pm 7.4$ Foxp $1^{+}$cells per section in embryos electroporated with Kir2.1/EGFP ( $p>0.05$, Student's $t$ test), demonstrating no change in total motor neuron number in embryos with inhibited activity ( $N=5$ for both EGFP- and Kir2.1/EGFP-treated embryos, $n=2085$ and 2094 neurons, respectively). Molecular identity of motor neurons was assessed by quantification of $\mathrm{Lim} 1^{+}$and Is $11^{+}$cells in EGFP- or Kir2.1/EGFP-electroporated embryos. In EGFP-electroporated embryos, $44 \pm 1.3 \%$ of Foxp1 ${ }^{+}$, EGFP $^{+}$cells expressed Lim1. In Kir2.1/EGFPexpressing embryos, $48 \pm 5 \%$ of Foxp $1^{+}$, EGFP ${ }^{+}$cells expressed $\operatorname{Lim} 1\left(N=5\right.$ for both EGFP ${ }^{+}$and Kir2.1/EGFP ${ }^{+}$ embryos, $n=334$ and 452 neurons, respectively). In EGFPelectroporated embryos, $52 \pm 6.4 \%$ of Foxp ${ }^{+}{ }^{+}$, EGFP $^{+}$cells expressed IsI1. In Kir2.1/EGFP-expressing embryos, $50 \pm$ $6.5 \%$ of Foxp $1^{+}$, EGFP $^{+}$cells expressed Is $11(N=4$ for $\mathrm{EGFP}^{+}$and $N=5$ for Kir2.1/EGFP ${ }^{+}$embryos, $n=396$ and 472 neurons respectively). Proportions of $\operatorname{Lim} 1^{+}$and $\mathrm{Is} \mid 1^{+}$ motor neurons in Kir2.1/EGFP- and EGFP-expressing embryos were not significantly different $(p>0.05$, Student's $t$ test). Values are plotted as the mean \pm SEM. $F$, Comparison between EphA4 expression in electroporated and unelectroporated sides of HH St. 29 spinal cords electroporated with Kir2.1/ EGFP. A region encompassing all EGFP ${ }^{+}$neurons in the Lim1 ${ }^{+}$LMC was selected on the electroporated side (green outline), then mean EphA4 intensity levels were measured in both that region and an equivalent region on the unelectroporated side. G, Quantification of EphA4 expression in the electroporated and unelectroporated sides of the LMC (left) and axons (right) of EGFP- and Kir2.1/EGFP-expressing embryos, expressed as a ratio. In the LMC, no difference is observed between EGFP- and Kir2.1/EGFP-expressing embryos (1.002: $1 \pm 0.06$ vs $1.07: 1 \pm 0.03 ; p>0.05$, Student's $t$ test). In axons, no difference is observed between EGFP- and Kir2.1/ EGFP-expressing embryos (0.96:1 \pm 0.11 vs 1.03:1 \pm 0.01 ; $p>0.05$, Student's $t$ test); $N=4$ embryos, $n>3$ sections per embryo. Values are expressed and plotted as the mean \pm SEM. Scale bars, $40 \mu \mathrm{m}$.
Figure 1. Suppression of activity by Kir2.1 does not change the number, molecular identity, or EphA4 expression levels in motor B. Neurons expressing either Hb9/EGFP (blue in the left panels) or Kir2.1/mCherry driven by the CMV promoter (red in the left promoter are largely inactive (green in the right panels). C, Quantification of spontaneous activity shows a reduction in firing rate in neurons expressing Kir2.1/EGFP (firing rate, $0.05 \pm 0.02$ events $/ \mathrm{min}$ ) compared with neurons expressing either Hb9/EGFP $(1.60 \pm 0.006$ events $/ \mathrm{min}, p<0.0001)$ or Kir2.1/mCherry $(1.53 \pm 0.09$ events $/ \mathrm{min}, p<0.0001)$. Consistent results were observed in each of three embryos examined per condition ( $>30$ neurons per condition). Values are expressed and plotted as the mean \pm SEM. D. Detection of Foxp1, Lim1, and EGFP in the LMC region of EGFP- and Kir2.1/EGFP-electroporated embryos. Dotted yellow lines delineate the ventrolateral extent of the spinal gray matter. $\boldsymbol{E}$, Motor neuron number was assessed by counting Foxp ${ }^{+}$nuclei in tissue sections of EGFP- or Kir2.1/EGFP-expressing embryos. We found, on average, $79 \pm 8.8$ Foxp $1^{+}$cells per 

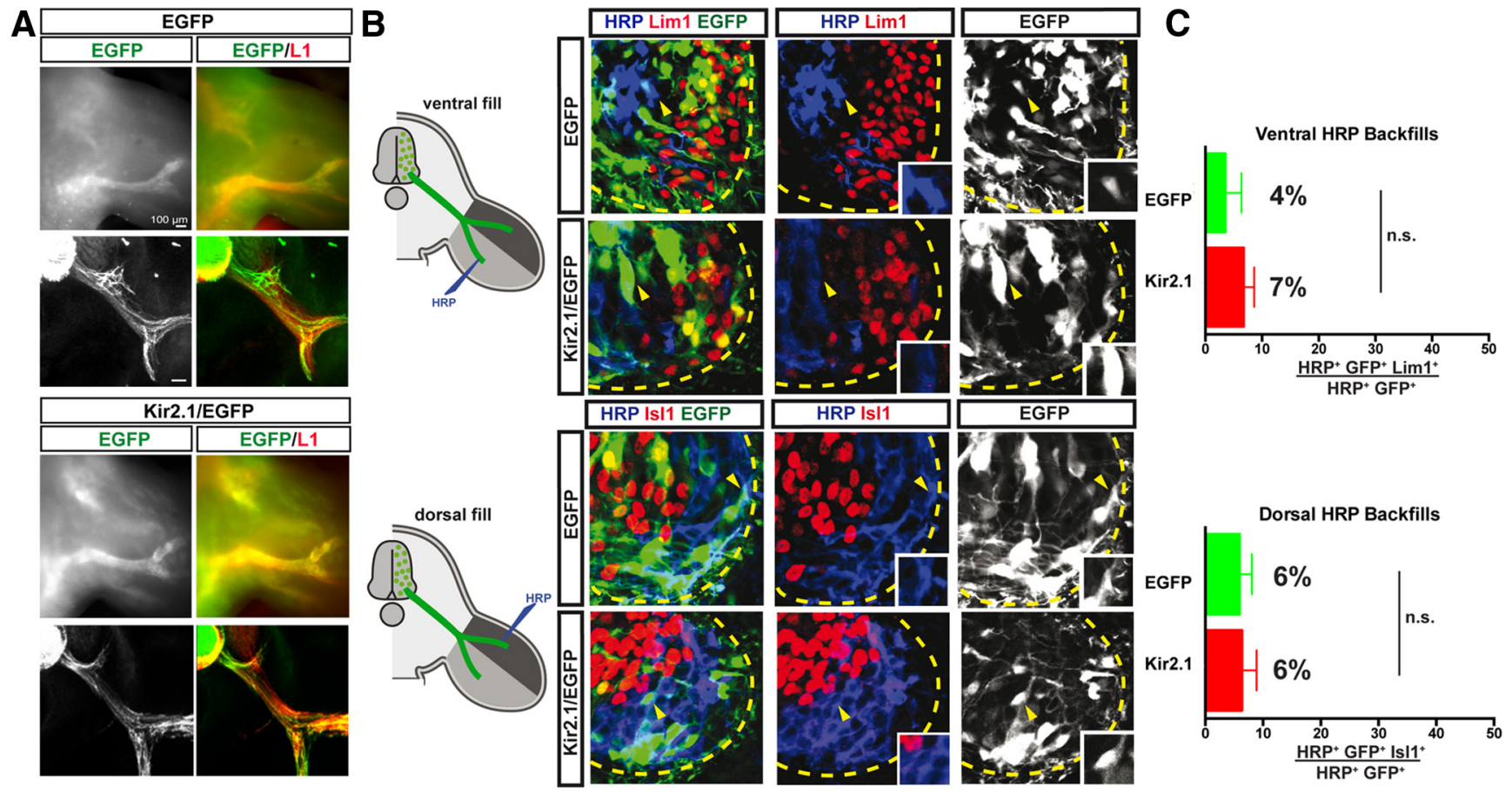

Figure 2. Suppression of activity by Kir2.1 expression does not affect the fidelity of LMC motor axon limb trajectories. A, Detection of L1 and GFP proteins in wholemounted limbs (top) or their sections (bottom) in chick HH st. 17/18 embryos electroporated with EGFP or Kir2.1/EGFP at HH st. 27/28. L1 protein (red) labels peripheral nerves, while green fluorescence labels only GFP ${ }^{+}$axons. No differences in outgrowth timing or pattern were noted. $\boldsymbol{B}$, Retrograde labeling of LMC neurons by HRP injections into ventral or dorsal hindlimb shank muscles of chick HH st. 29/30 embryos expressing EGFP or Kir2.1/EGFP. Images show detection of HRP (blue), Lim1 or Is1 ( red), and EGFP (green) in the LMC region of EGFP- or Kir2.1/EGFP-electroporated embryos injected with HRP into ventral (top) or dorsal (bottom) shank muscles. Insets in images show Lim1 ${ }^{-}$or Is $11^{-}$MN electroporated with EGFP or Kir2.1/EGFP and backfilled, as expected, by ventral or dorsal fills (indicated with yellow arrowheads). C, Proportions (\%) of electroporated and backfilled lateral or medial LMC MN in embryos injected with HRP into ventral or dorsal shank muscles. In ventrally filled

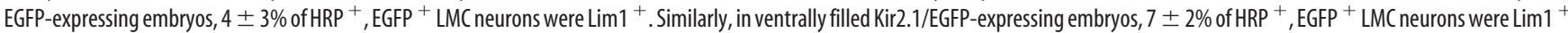

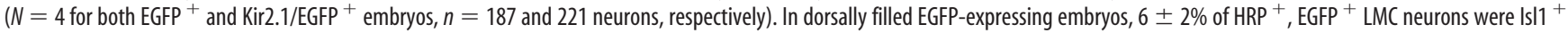
Similarly, in dorsally filled Kir2.1/EGFP-expressing embryos, $6 \pm 3 \%$ of HRP ${ }^{+}$, EGFP ${ }^{+} \mathrm{LMC}$ neurons were $\mathrm{Is} 11^{+}\left(\mathrm{N}=3\right.$ for both EGFP ${ }^{+}$and Kir2.1/EGFP ${ }^{+}$embryos, $n=172$ and 293 neurons, respectively). Proportions of HRP ${ }^{+}$, EGFP ${ }^{+}$lateral or medial LMC neurons in ventrally or dorsally filled Kir2.1/EGFP-expressing embryos and those in ventrally or dorsally filled EGFP-expressing embryos are not significantly different ( $p>0.05$; Student's $t$ test). Error bars indicate SEM. All values are expressed and plotted as the mean \pm SEM. Scale bars, $40 \mu \mathrm{m}$.

cence intensity within each bin SC [SC superior colliculus fluorescence intensity (SCFI)] was measured using Image J software. Fluorescence measures were normalized to the fluorescence intensity in the corresponding electroporated retina (RFI): SCFI/RFI.

To quantify electroporated retinal axons in the SC of P9 mice, three reconstructed serial sections from each animal were conformed to a single common template of the SC. The common template represents a sagittal slice cut through the center of the SC at a mediolateral coordinate where the dorsal layer is relatively homogeneous and flat. The common template was chosen to minimize the mean square distortion arising from piecewise-linear conformation of tissue sections from individual animals. Sections were linearly scaled to the mean thickness of the superficial layer of the SC, and fluorescence levels were measured along the rostrocaudal axis of the SC. Collicular sections were divided in 124 homogeneous bins to gauge the spatial distribution of the terminal arbors. We used a bin-by-bin one-way ANOVA to quantify the differences between the distributions of fluorescence intensity. Individual axons in electroporated P9 mice were reconstructed using an Imaris work station, and width, density, and distance to the SC surface were measured.

\section{Results}

\section{Motor neuron specification and axon pathfinding are} activity-independent processes

To determine whether intrinsic electrical activity is required for neural specification and axon navigation, we first focused on LMC neurons, which have been used to study the role of neural activity in early neuronal development and whose molecular identity is linked to myotopically organized axon projections (Tsuchida et al., 1994; Kania and Jessell, 2003; Hanson and
Landmesser, 2004, 2006; Hanson et al., 2008; Plazas et al., 2013). We first examined how overexpression of the inwardly rectifying potassium channel Kir2.1, previously used in other systems (Burrone et al., 2002; Yamada et al., 2010), affected spontaneous activity in developing chick LMC neurons. Mixtures of plasmids encoding either the R-GECO or G-GECO calcium indicators (Zhao et al., 2011) alongside those encoding EGFP driven by the Hb9 promoter (Hb9-EGFP) or Kir2.1 driven by either the strong CAG promoter enhancer (Fig. 1A, Kir2.1/EGFP) or the weaker CMV promoter enhancer (Kir2.1/mCherry) were coelectroporated into the chick spinal cord at $\mathrm{HH}$ st. 18/19, and the neural activity of LMC neurons was assayed at HH st. 29 (Hamburger and Hamilton, 1992). Neurons expressing Hb9-EGFP were robustly active (1.6 events/min), but expression of the CAG-driven Kir2.1 (Kir2.1/EGFP) almost entirely blocked activity in chick neurons (0.05 events/min), although CMV-driven expression (Kir2.1/mCherry) was not sufficient to block activity (1.53 events/min; Fig. $1 B, C$ ). These data demonstrate that overexpression of Kir2.1/EGFP from the CAG promoter enhancer is sufficient to block spontaneous activity, allowing us to examine how this activity influences the development of LMC neurons in a cell-autonomous fashion.

The myotopically relationship between LMC neurons and their limb targets is revealed by the differential expression of LIM homeodomain transcription factors Lim1 and Isl1. Lateral LMC neurons express Lim1 and innervate dorsal limb muscles, while medial LMC neurons express Isl1 and innervate ventral limb 
A

\section{Electroporation at E13}

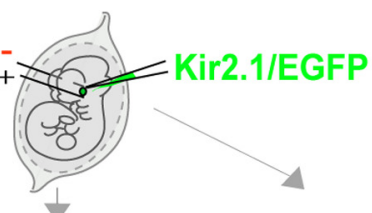

Calcium Imaging

in P0/P4 wholemount retina
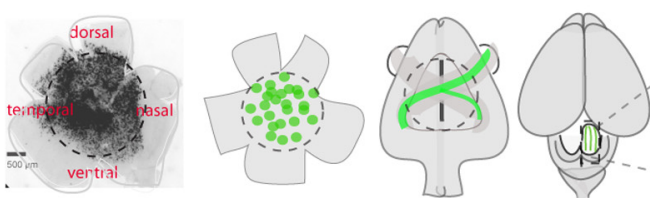

4

C
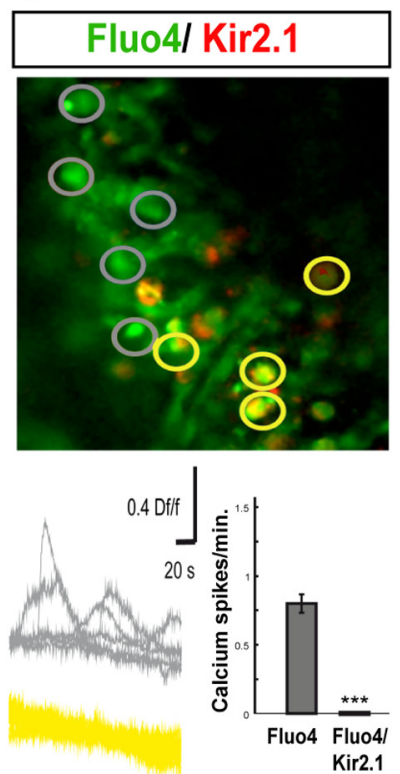

E
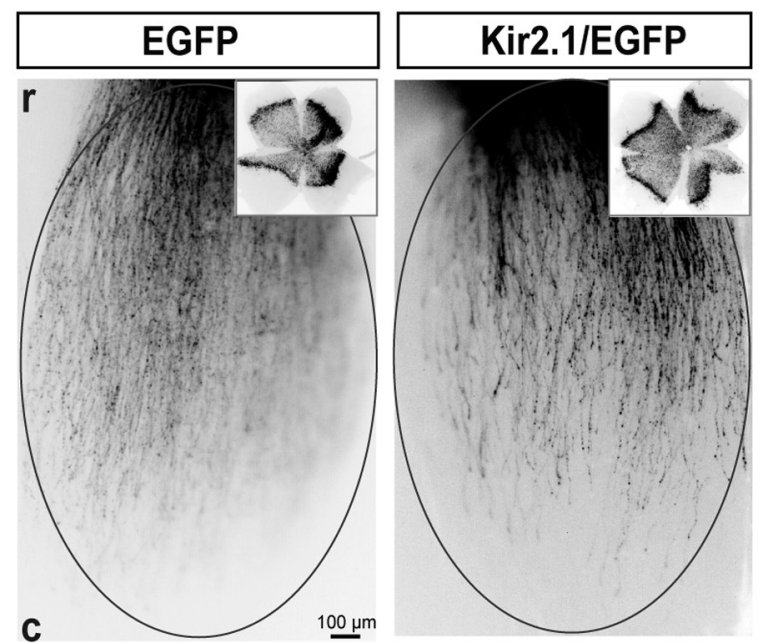

D

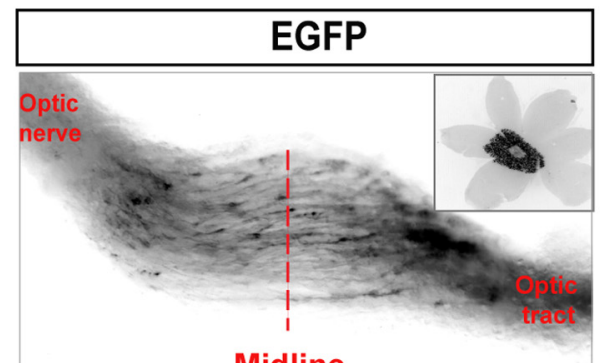

$100 \mu \mathrm{m}$

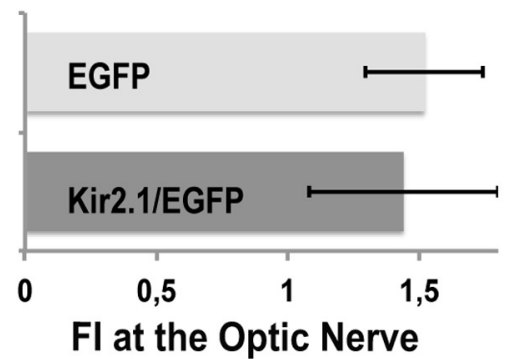

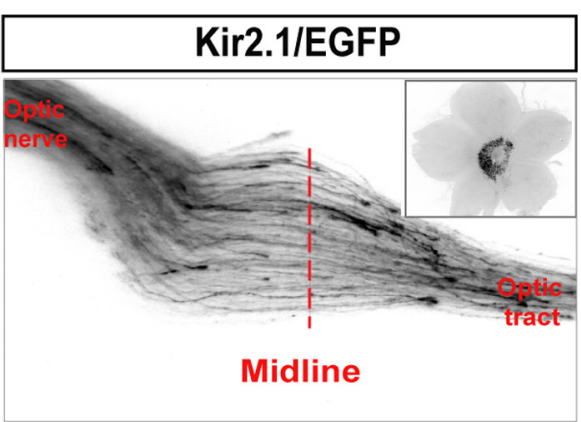

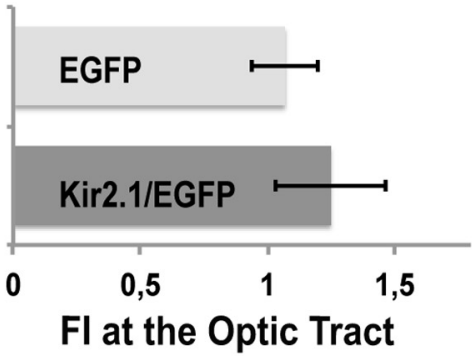

F

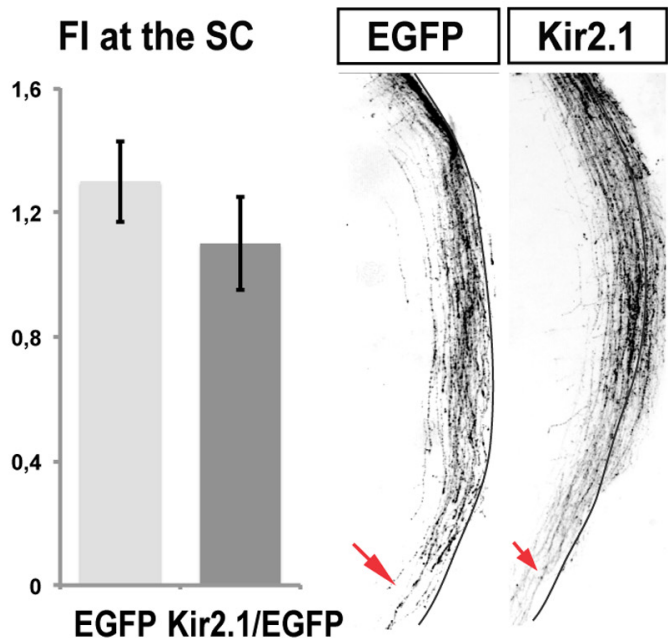

FI in sections

(Arbitrary units)

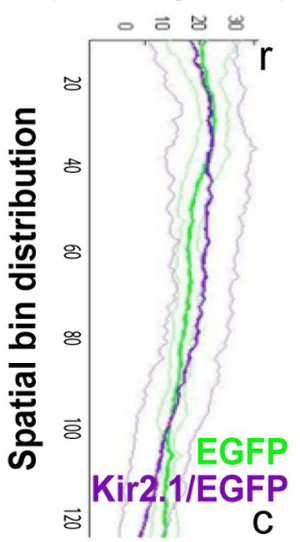

Figure 3. Spontaneous activity is not required for RGC axon pathfinding or targeting to the SC. $\boldsymbol{A}$, Schema summarizing the experimental procedures. The different plasmids were injected into the retina of E13 embryos by in utero electroporation. Only those retinas electroporated in equivalent central areas such as the electroporated retina shown in the image were considered for further analysis. Wholemount retinas of electroporated mice collected at postnatal stages were used for calcium imaging experiments. Axons from targeted RGCs were analyzed at the optic chiasm level in E16 embryos, and at P0 and P9 in the SC. $\boldsymbol{B}$, Wholemount retinas from mice electroporated at E13 with Kir2.1/EGFP plasmids dissected at P9 and incubated with anti-Kir2.1 antibodies (red) demonstrate that Kir2.1 is coexpressed in targeted RGCs. C, Representative image of a calcium imaging experiment performed in retinas electroporated with Kir2.1/DsRed. Gray regions of interest represent cells loaded with Flu04, and yellow regions of interest represent cells electroporated with Kir2.1/DsRed and loaded with Fluo4. Waveforms (middle) show overlaid examples of calcium activity taken from the regions of interest shown in the image. The histogram represents the absence of calcium transients in the Kir2.1/DsRed-electroporated RGCs and the normal pattern of spontaneous calcium activity in the Flu04 control cells (gray bar). Thirty-three cells from five animals electroporated with EGFP, and 56 cells from five animals electroporated with Kir2.1/DsRed were used for quantification. ${ }^{* * *} p<0.001$ (Student's unpaired $t$ test). Values are expressed as the mean \pm SEM. D, RGC axons from embryos electroporated with Kir2.1/EGFP (Figure legend continues.) 
muscles (Tsuchida et al., 1994). Because pharmacological manipulation of neuronal activity appears to affect the expression of Isl 1 and Lim1 in motor neurons (Hanson and Landmesser, 2004, 2006), we reasoned that spontaneous activity may be important for the specification of LMC neuron molecular identity and therefore that blocking activity with Kir2.1/EGFP might alter the numbers of LMC neurons that express Isl1 or Lim1. To assess this, we electroporated chick embryos, as described above, and monitored the expression of the general LMC neuron marker Foxp1 (Dasen et al., 2008; Rousso et al., 2008), alongside Lim1 and Isl1 as markers of medial and lateral LMC neurons, respectively. The number of Foxp ${ }^{+}$neurons did not differ significantly between embryos electroporated with EGFP and Kir2.1/EGFP (79 Foxp $1^{+}$cells per LMC section in EGFP vs 70 in Kir2.1/EGFPelectroporated embryos; Fig. 1D,E). In EGFP-expressing spinal cords, $44 \%$ of Foxp $1^{+}$, EGFP ${ }^{+}$LMC neurons expressed Lim1 (Fig. $1 D, E$ ). Similarly, in Kir2.1/EGFP-expressing embryos, $48 \%$ of FoxP $1^{+}$, EGFP ${ }^{+}$LMC neurons expressed Lim1 (Fig. 1D,E). The proportion of Isl1-expressing LMC neurons was not different between the two groups either $\left(52 \%\right.$ in $\mathrm{EGFP}^{+}$LMC neurons and 50\% in Kir2.1/EGFP ${ }^{+}$LMC neurons; Fig. 1E), demonstrating that LMC identity is not altered by spontaneous activity blockade.

Previous studies have demonstrated that a global, pharmacologically induced decrease in activity lowers the expression of Eph receptors in LMC neurons and leads to LMC axon guidance errors (Hanson and Landmesser, 2004; Kastanenka and Landmesser, 2010), raising the question of whether blocking neural activity in a cell-autonomous manner might have a similar effect. Chick embryos were electroporated as described above with either EGFP or Kir2.1/EGFP, and the expression of EphA4 was analyzed in $\mathrm{EGFP}^{+}$, $\mathrm{Lim}^{+}{ }^{+} \mathrm{LMC}$ neurons at HH st. 29 (Fig. $1 F$ ). EphA4 expression levels, measured as fluorescence intensity in regions containing high numbers of $\mathrm{EGFP}^{+}, \mathrm{Lim}^{+}$neurons on the electroporated side, were compared with corresponding regions on the unelectroporated side. The ratio between EphA4 signal on the electroporated and unelectroporated sides in EGFPexpressing embryos was 1.002:1, which was not significantly different from the ratio in Kir2.1/EGFP-expressing embryos (1.07: 1), demonstrating that blockade of activity does not alter EphA4 expression in the LMC cell body. Axonal EphA4 expression was assessed in a similar fashion, in spinal ventral roots showing robust EGFP expression. The electroporated/unelectroporated

$\leftarrow$

(Figure legend continued.) plasmids or EGFP alone show similar behavior at the optic chiasm level. Corresponding electroporated retinas are shown on the right. Graph at the left represents mean \pm SEM fluorescence intensity at the optic nerve level normalized to the retinal fluorescence intensity ( $p=0.42$, Student's unpaired $t$ test). Graph at the right represents the mean of fluorescence intensity at the contralateral optic tract level normalized to the retinal fluorescence intensity ( $p=0.27$, Student's unpaired $t$ test). Error bars indicate SEM. All values are expressed and plotted as the mean \pm SEM. Ten mice were used to measure fluorescence intensity in each condition. $\boldsymbol{E}$, Representative examples of the SC (top view) of newborn mice that were electroporated at E13 with the indicated plasmids. Corresponding retinas are shown on the right corner. Graphs represent the mean fluorescence intensity in wholemount SCs normalized to fluorescence intensity in the retina ( $p=0.44$, Student's unpaired $t$ test). Error bars indicate $S E M$. All values are expressed and plotted as the mean \pm SEM. Eight mice were used to measure fluorescence intensity in each condition. $r$, Rostral; $c$, caudal. $\boldsymbol{F}$, Representative sagittal sections through the medial SC. Red arrowheads indicate the termination of the majority of the targeted axons. Graphs represent the mean fluorescence intensity (FI) from three consecutive sections of the SCS of electroporated mice. Error bars indicate SEM. All values are expressed and plotted as the mean \pm SEM. Five mice were used to measure fluorescence intensity in each condition. There are no significant differences between the behavior of axons electroporated with Kir2.1/ EGFP or EGFP alone (one-way ANOVA). ratio was not significantly different: 0.95:1 in EGFP-treated embryos, and 1.02:1 in Kir2.1/EGFP-treated embryos. Thus, cellautonomous spontaneous activity blockade does not affect EphA4 protein expression on cell bodies or axons (Fig. $1 F, G$ ).

We next asked whether, as previously suggested, spontaneous activity is important for the guidance of LMC axons, possibly by modulating EphA4 function (Hanson and Landmesser, 2004). Thus, we examined the limb trajectories of LMC axons expressing either EGFP or Kir2.1/EGFP in embryos electroporated with expression constructs, as described above. Termini of EGFP ${ }^{+}$ axons in EGFP and Kir2.1/EGFP were found at a similar distance from the spinal cord as those of neurofilament-expressing unelectroporated axons, and in untreated embryos (Fig. 2A; data not shown), suggesting that spontaneous activity is not required for LMC axon outgrowth. Next, we examined whether lateral and medial LMC neurons select their appropriate limb nerve trajectory in the absence of spontaneous activity. To do this, we injected the retrograde tracer HRP into the dorsal or ventral limb of electroporated embryos, and determined the molecular identity of labeled LMC neurons. If spontaneous activity is important for limb nerve selection by LMC axons, then dorsal limb injections are expected to label a significant number of medial LMC neurons that normally innervate the ventral limb, and ventral limb injections are expected to label a significant number of lateral LMC neurons that normally innervate the dorsal limb. In embryos with a ventral limb HRP injection, the proportion of all EGFP ${ }^{+}, \mathrm{HRP}^{+} \mathrm{LMC}$ neurons that were also $\mathrm{Lim}^{+}{ }^{+}$was not significantly different between EGFP- and Kir2.1/EGFPelectroporated embryos ( $4 \%$ and $7 \%$, respectively; $p>0.05$, Student's $t$ test; Fig. 2B). Similarly, in embryos with a dorsal limb HRP injection, the proportion of all $\mathrm{EGFP}^{+}, \mathrm{HRP}^{+} \mathrm{LMC}$ neurons that were also Isl1 ${ }^{+}$was not significantly different between EGFP- and Kir2.1/EGFP-electroporated embryos ( $6 \%$ for both; $p>0.05$, Student's $t$ test; Fig. $2 C$ ). Together, these results argue strongly that the molecular specification of LMC neurons and the selection of axon trajectory in the limb occur independently of spontaneous activity.

\section{Spontaneous activity is dispensable for RGC axon pathfinding and SC targeting}

We next probed, in vivo, the role of spontaneous activity in the development of graded topographic projections of RGC neurons, where it has been previously suggested to be important in an in vitro setting (Nicol et al., 2007). Because spontaneous activity has been reported in the embryonic retina (Galli and Maffei, 1988), we first analyzed whether activity plays a role in the processes that occur between embryogenesis and birth such as RGC axon guidance in the optic nerve and chiasm or targeting to the SC. Using in utero electroporation, Kir2.1/EGFP- or EGFP-encoding plasmids were ectopically expressed in mouse RGCs at embryonic day 13 (E13) and their axonal projections analyzed at two different stages: at E16, when most axons leave the optic chiasm; and at P0, upon axon arrival to the SC. Ectopic expression of Kir2.1 and functional blockade of spontaneous activity were confirmed in electroporated RGCs, and calcium imaging experiments demonstrated that, as in the spinal cord, Kir2.1 expression blocks activity in retinal cells $(0.7$ events/min in control vs 0 events $/ \mathrm{min}$ in Kir2.1/EGFP-expressing cells; $p<0.001$; Fig. $3 A-C$ ).

We then examined the behavior of RGC axons within the optic chiasm. Quantification of the number of axons expressing Kir2.1/EGFP visualized at the optic chiasm normalized to the number of electroporated RGC in the retina showed no significant differences in growth or projection patterns when compared 
A

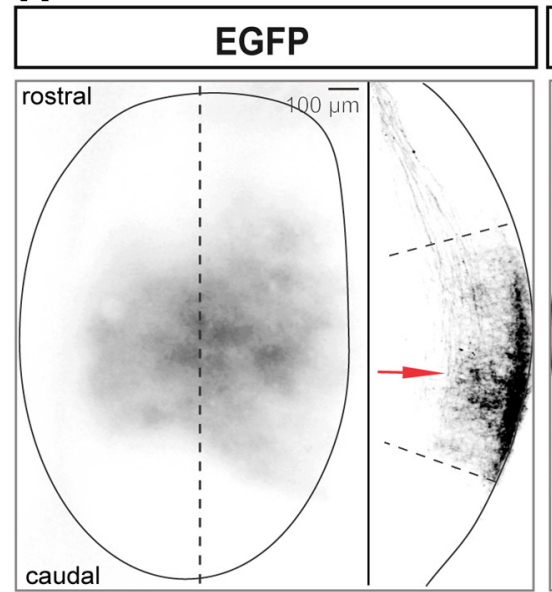

B

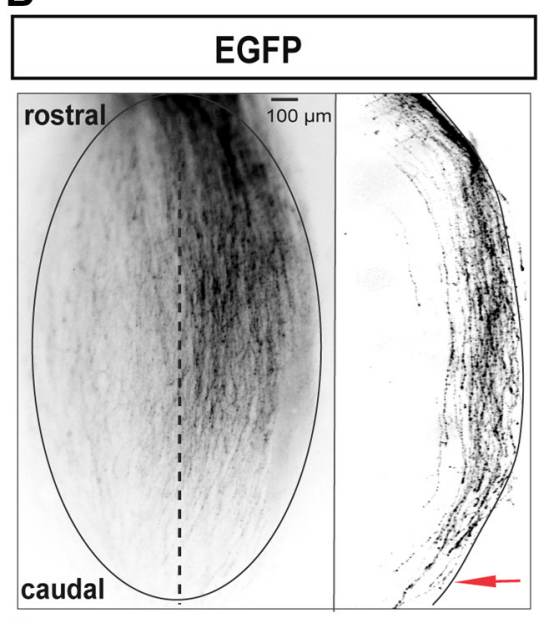

C

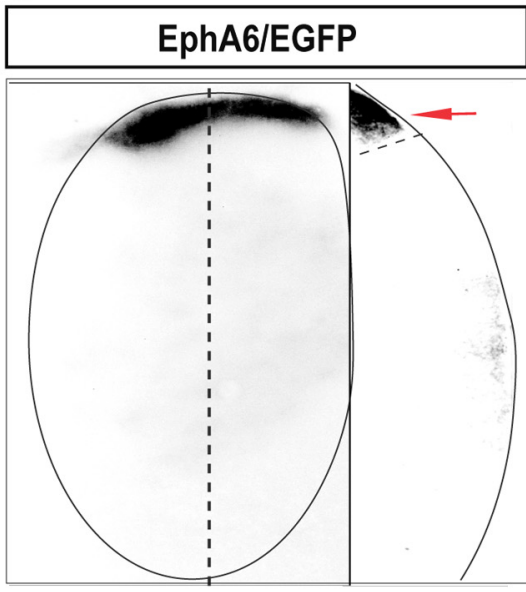

D

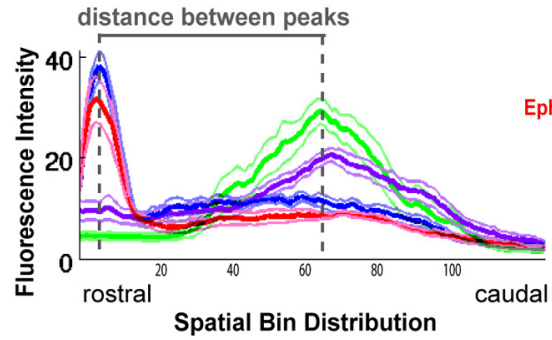

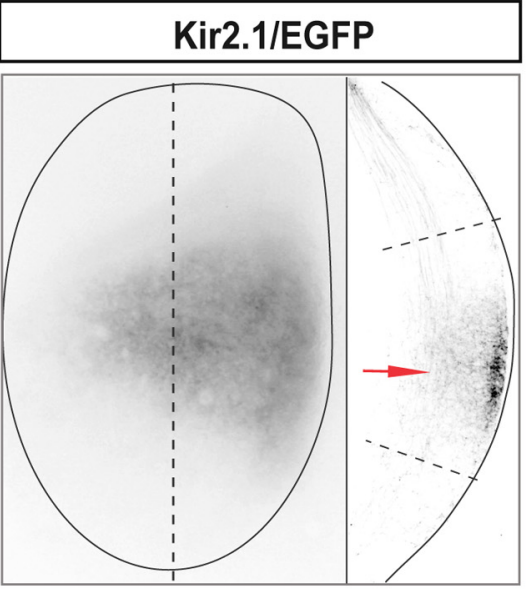

Fluorescence Intensity
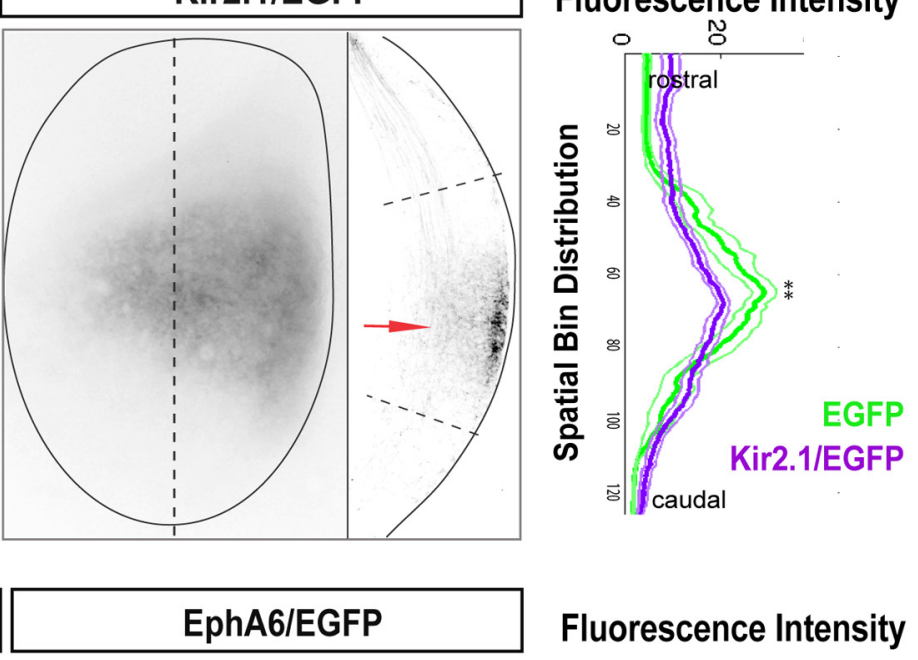

Fluorescence Intensity
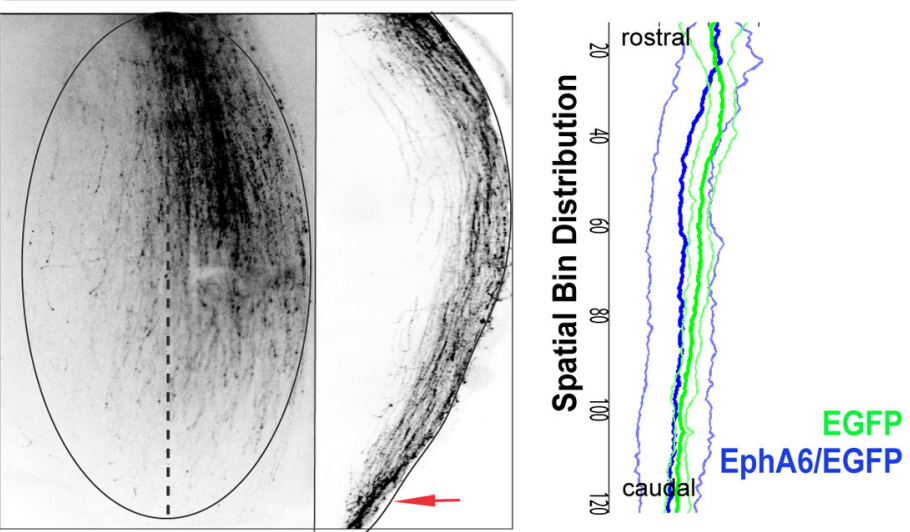

Fluorescence Intensity
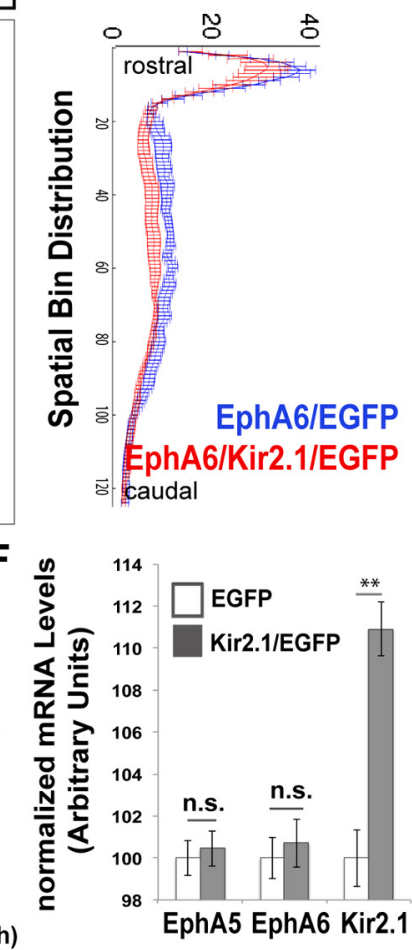

Figure 4. Spontaneous activity is not necessary to transduce EphA/ephrinA signals during the establishment of the rostrocaudal visual map. $\boldsymbol{A}$, Representative examples of the SC of P9 mice electroporated at E13 with the indicated plasmids. Top views of the SCs and sagittal sections through the SC at the level indicated by the dotted line are shown. Red arrows point (Figure legend continues.) 
with control axons expressing EGFP ( $p=0.42$ for measures at the optic nerve and $p=0.27$ for measures at the optic tract; Fig. $3 D$ ). Upon arrival at the $\mathrm{SC}$, rather than directly targeting their correct topographical site, RGC axons initially overshoot their prospective termination zone (TZ) and extend caudally. Comparison of SCs from P0 mice electroporated with Kir2.1/EGFP to those electroporated with EGFP revealed no significant differences in timing or quantity of axons reaching the caudal SC of newborn mice ( $p=0.44$; Fig. $3 E$ ). This demonstrates that the blockade of RGC activity at early stages of development does not affect the pathfinding of their axons, or their arrival at the optic chiasm or the SC; therefore, it is highly unlikely that the expression of, and the signaling mediated by, the guidance molecules controlling these processes require spontaneous activity.

\section{EphA can redirect RGC axons in the absence of spontaneous activity}

We next asked whether the expression and function of EphA/ ephrinAs requires spontaneous activity. First, we tested whether the expression of EphA receptors is affected by activity blockade. In the mouse retina, the only members of the EphA family expressed in a low-nasal to high-temporal gradient that control the establishment of topographic maps are EphA5 and EphA6 (Feldheim et al., 2004; Reber et al., 2004; Carreres et al., 2011). It has been already shown that the expression of EphA5 does not change after postnatal injections of epibitadine into the eye or after treatment with tetrodotodoxin (Pfeiffenberger et al., 2005; Nicol et al., 2007). However, the expression of neither EphA5 nor EphA6 receptors has been analyzed after activity blockade at early embryonic stages, when these molecules are already highly expressed in the temporal retina. To investigate whether activity may alter the expression of EphA5/A6 receptors at early stages, retinas electroporated at E13 with Kir2.1/EGFP or EGFP expression plasmids were isolated to measure the levels of EphA6 and EphA5 mRNAs by qRT-PCR. DNA primers targeting Kir2.1 mRNA were

\footnotetext{
$\leftarrow$

(Figure legend continued.) to the most intense fluorescence area in each case. Graphs represent fluorescence intensity (mean \pm SEM) from three consecutive sections of P9 electroporated mice (seven mice were used to measure fluorescence intensity in each condition). No significant differences between both graphs were observed in the distance of the $T Z$ (peak of fluorescence) to the rostral SC $(p=0.02)$, although the termini distribution at the TZ of Kir2.1/EGFPexpressing mice was wider than that of controls $(p=0.0004)$. $\boldsymbol{B}$, Representative example of $\mathrm{PO}$ SCs electroporated at E13 with EphA6/EGFP or EGFP alone plasmids. Top views of the SC and sagittal sections through the $\mathrm{SC}$ at the level indicated by the dotted line are shown. Red arrows indicate the termination of the majority of targeted axons. Graphs represent the mean \pm SEM fluorescence intensity from three consecutive sections of the SCs of electroporated mice (five mice were used to measure fluorescence intensity in each condition). The graphs show no significant differences in behavior among the axons electroporated with EphA6/EGFP or EGFP alone (one-way ANOVA). C, Representative examples of the SC of P9 mice electroporated at E13 with the indicated plasmids. Top views of the SCs and sagittal sections through the $\mathrm{SC}$ at the level indicated by the dotted line are shown. Red arrows point to the most intense fluorescence area in each case. Graphs represent fluorescence intensity (mean \pm SEM) from three consecutive sections of P9 electroporated mice (seven mice were used to measure fluorescence intensity in each condition). No significant differences were observed between both graphs. D, Overlay demonstrates that fluorescence intensity peaks from samples expressing either EGFP or Kir2.1/ EGFP and samples expressing either EphA6 or EphA6/Kir2.1 are very distant. E, Distance of RGC axons electroporated with the indicated plasmids to the most rostral point of the SC. Units are the percentage of the total collicular length once individual sections were conformed to a SC template. Values are plotted as the mean \pm SEM. ${ }^{* * *} p<0.001$, Student's unpaired $t$ test. n.S., Not significant. $\boldsymbol{F}$, Graphs show mRNA levels for EphA5 and EphA6 in E16 retinas of embryos electroporated at E13 with EGFP alone or with Kir2.1/EGFP plasmids. Ten retinas/condition were pooled per experiment. The average of four experiments is shown. Values are plotted as the mean \pm SEM. ${ }^{* *} p<0.01$, Student's unpaired $t$ test.
}

used as controls to be sure that ectopic Kir2.1 was induced in the tested samples. While the levels of Kir $2.1 \mathrm{mRNA}$ increased $>10 \%$ in retinas electroporated with Kir2.1/EGFP plasmids compared with those electroporated with EGFP, the levels of EphA5 and EphA6 mRNA were similar to those electroporated with EGFP plasmids, confirming that spontaneous activity is not required to induce EphA5 or EphA6 mRNA (Fig. $4 F$ ) and that the lack of activity does not affect endogenous retinal EphA transcription.

Given that axon guidance receptors relevant to RGC targeting were normally expressed in the absence of activity, we asked whether activity is required for RGC axon guidance, possibly at the level of EphA receptor signaling. After birth, following initial target overshoot, RGC axons in the caudal SC retract to their topographically accurate $\mathrm{TZ}$ and form interstitial branches rostral to it (Nakamura and O'Leary, 1989; Simon and O'Leary, 1992). Thus, during this initial phase, the precise $T Z$ where individual axons will arborize in superficial layers is determined (Phase 1: retraction/topography phase). Then, complex arbors develop at the TZ, followed by the elimination of major segments of RGC axons that are distal to the TZ, together with branches and arbors that formed at topographically incorrect positions (Phase 2; remodeling phase; Nakamura and O'Leary, 1989). We reasoned that according to the classical model of activityindependent axon guidance, Kir2.1 expression should only affect the remodeling phase of RGC termination in the SC. In contrast, if activity were important for the retraction/topography phase, silencing RGC activity with Kir2.1 expression should result in a TZ position shift. To resolve between these alternatives, terminals of axons expressing Kir2.1/EGFP or EGFP were analyzed in the SC of P9 mice. Both EGFP- and Kir2.1/EGFP-expressing axons projected to equivalent central areas of the SC. The distance of the TZ (TZd; peak of fluorescence) to the rostral SC was $52 \%$ of the total SC length for EGFP-expressing axons and 54\% for Kir2.1/ EGFP-expressing axons $(p=0.2)$, although the termini distribution at the TZ of Kir2.1/EGFP-expressing mice was wider than that of controls (half-width-half-height of the fluorescence peak; $16 \%$ vs $21 \%$ of total $S C$ length, respectively; $p=0.0004$; Fig. $4 A$ ).

We then asked whether signaling downstream of EphA/ephrinAs is modulated by activity by testing whether a phenotype caused by overexpression of Eph receptors can be suppressed by activity blockade. Ectopic electroporation of EphA6 in embryonic central retina resulted in RGC axonal projection to rostral collicular areas (TZd, 5\%; Fig. 4C; Carreres et al., 2011) after overshooting their normal TZ at birth (Fig. 4B). Axons expressing Kir2.1/EGFP and EphA6 also projected to the rostral colliculus (TZd, $4 \%)$, a behavior not significantly different $(p=0.6)$ from that of axons expressing only EphA6/EGFP (Fig. 4C-E). Together, our findings demonstrate that RGC axon guidance and EphA/ephrinA signaling occur normally in the absence of spontaneous activity.

\section{Spontaneous activity is essential for axon arborization and pruning at the RGC terminal zone}

Activation of EphA/ephrinA signaling in axon retraction and establishment of the TZ do not depend on spontaneous activity. However, as in previous results reporting defects in collicular organization of RGC terminals in the absence of spontaneous activity (McLaughlin et al., 2003; Dhande et al., 2011), we found that in the SC of P9 mice, the termini of axons expressing Kir2.1/ EGFP were more dispersed and showed lower fluorescence intensity compared with the controls (Fig. 4A), suggesting a significant change in their morphology and indicating that spontaneous activity is important for RGC mapping. To define the precise func- 
tion of spontaneous activity in this process, we examined the axonal arbor structure of individual RGCs in the SC (see Experimental procedures). Reconstruction analysis revealed that arbors of Kir2.1/EGFP-expressing axons occupy a wider TZ area (arbor width: $276 \mu \mathrm{m}$ ) that is deeper relative to the surface of the SC (length to the surface: $102 \mu \mathrm{m}$ ) than in controls (arbor width: $198 \mu \mathrm{m}$; length to the surface: $30 \mu \mathrm{m} ; p=0.007$ and $p=$ 0.002 , respectively; Fig. $5 A, B)$. In general, Kir2.1/EGFP-expressing arbors were less elaborate (arbor density: 19\%) than those from cells expressing EGFP (arbor density: $56 \%$; $p=0.001$ ); however, the point along the rostrocaudal axis of the SC at which axons establish their TZ was located at a similar distance from the rostral SC in both conditions (Figs. 4, 5A,B). Collaterals outside the terminal zones were rarely found in Kir2.1/EGFP- or in EGFP-electroporated axons. These results clearly demonstrate a role of spontaneous activity in the formation of the visual circuits at the level of local pruning and branching of RGC axons once they reach their TZ.

\section{Discussion}

For decades, experimental and computational studies have suggested that genetic factors and spontaneous activity play complementary but independent roles in the development of precise neural circuits and topographic maps. More recent experimental evidence suggests that these two mechanisms could interact extensively, with spontaneous activity regulating earlier events during the development of neural circuits. The in vivo results presented here in a setting that comprises all steps of neural development from early neural specification to late refinement processes, demonstrate that in birds and mammals, early and late phases of topographic map development differ markedly in their requirement for spontaneous activity. Activity does not play a significant role in neural specification, axonal pathfinding decisions, or gross topography but is fundamental at a later stage to properly refine the axonal terminals once at the termination zone in the target tissues. Furthermore, our results in chick and mouse disengage the postulated coupling of EphA/ephrinA signaling to spontaneous activity in axon guidance and initial map formation.

\section{Spontaneous activity in early stages of circuit formation}

The improved techniques that detect modest changes in $\mathrm{Ca}^{2+}$ levels have been used as surrogate indicators of embryonic neural activity (Goodman and Spitzer, 1981; Maffei and Galli-Resta, 1990). The current robust evidence on the existence of early neural activity raised the possibility that different developmental processes such as cell specification, cell migration, axonal growth
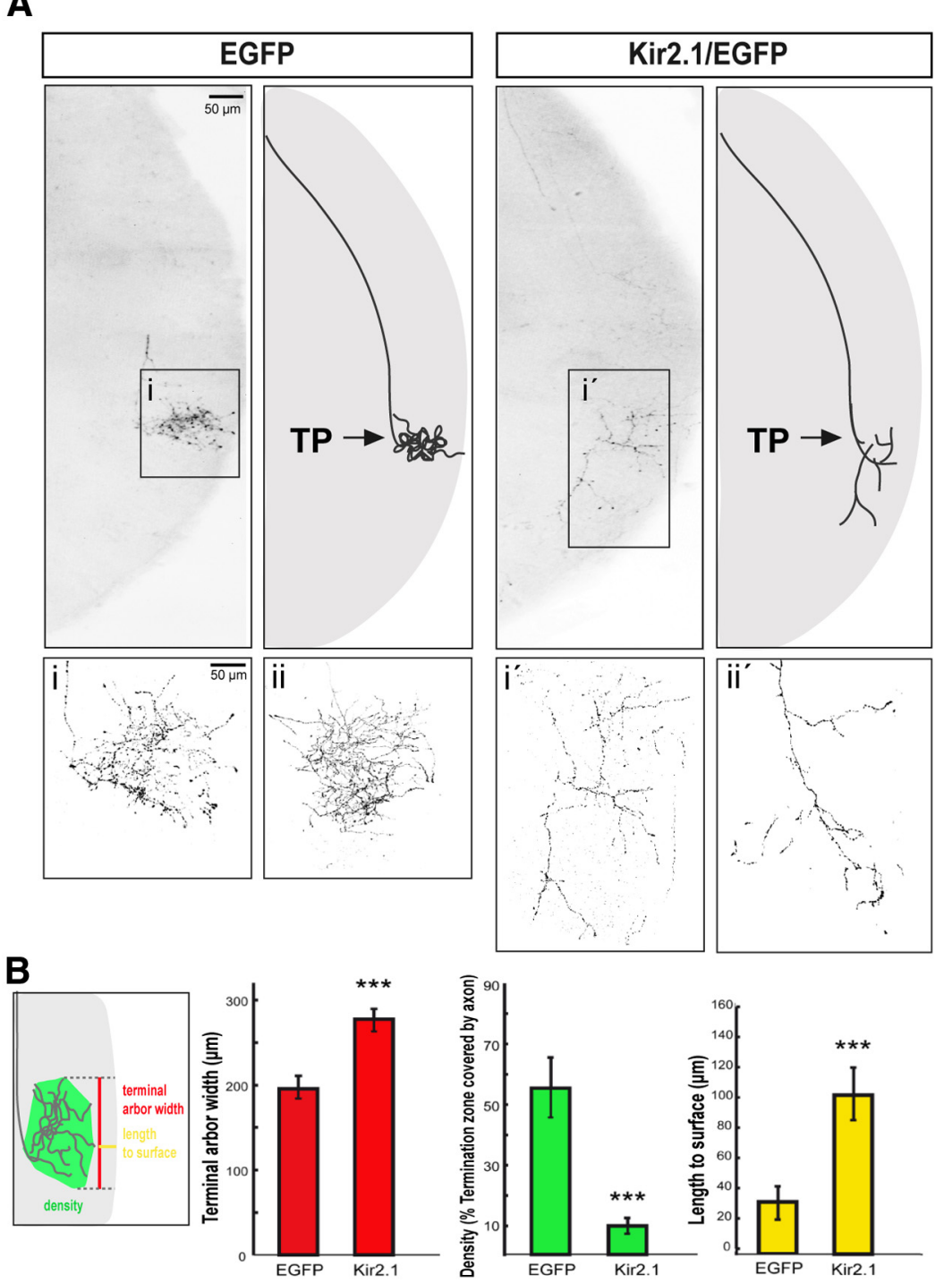

Figure 5. Spontaneous activity is required for local axon remodeling at the terminal zone. $\boldsymbol{A}$, Representative sagittal sections from the SC of P9 mice electroporated with EGFP alone or Kir2.1/EGFP. Axons show similar turning points (TP; arrows) along the rocaudal axis of the $S C$ in both cases, as it corresponds to the central location of their cell bodies in the retina. Right panels are with EGFP alone. $\boldsymbol{i}, \boldsymbol{i}^{\prime}$, Close-up images of the squared areas. $\boldsymbol{i i}, \boldsymbol{i i}^{\prime}$, More examples of terminal axons expressing EGFP or rs; density, green bars) in Kir2.1/EGFP-expressing axons $(n=8)$ and in the controls expressing EGFP alone $(n=9)$. Values are plotted as the mean \pm SEM. ${ }^{* * *} p<0.001$, Student's unpaired $t$ test.

rate, axon pathfinding, and axon targeting could be also instructed by spontaneous activity (Spitzer, 2006). Thus, in recent years, spontaneous activity has been postulated as an important mechanism that may modulate early developmental stages in different brain systems and species. In contrast to this mounting evidence, we find that silencing neural activity in individual LMC neurons or RGCs does not alter the neuronal fate or axon guidance decisions of LMC neurons, or affect the choices of visual axons in decision points such as the optic chiasm.

The discrepancy between our observations and the previous experiments in chick motor neurons could be attributed to the method used to block spontaneous activity; we studied the effect of the expression of Kir2.1 at the level of single cells, whereas Hanson and Landmesser (2004) used a pharmacological treat- 
ment using picrotoxin. Picrotoxin inhibits $\mathrm{GABA}_{\mathrm{A}}$ receptors, and it is known that GABA can act as an axon guidance cue (Ferguson and McFarlane, 2002). Therefore, it is possible that picrotoxin treatment influences axon guidance processes via GABA signaling rather than through activity inhibition. However, more recently, it has been shown that blocking activity in individual zebrafish motor neurons by ectopic expression of Kir2.1 causes pathfinding errors as well (Plazas et al., 2013). One critical difference between these results and ours is the influence of the speciesspecific embryonic environment. In our study, we examined mouse and chick embryos, which are cosseted in a very highly regulated environment to develop into terrestrial animals. In contrast, most of the experiments in which activity seems to influence early developmental events have been performed in organisms that develop and subsequently live in aquatic environments, which may be subject to changes in salt concentration (Nishiyama et al., 2003; Demarque and Spitzer, 2010; Plazas et al., 2013). By allowing the environment to influence the number of excitatory and inhibitory neurons in the nervous system as in the study of Borodinsky and Spitzer (2007), aquatic embryos may be able to adapt the wiring of their nervous system to their environment more readily than avian or mammalian embryos.

In mammals, the loss of neural activity has been reported to affect the expression of axon guidance molecules. In the embryonic thalamus, for example, ectopic expression of Kir2.1 increases the expression of Robol receptor (Mire et al., 2012). It is possible that the expression of some families of guidance molecules, such as Robo/Slits, is more sensitive to neural activity than others such as EphA/ephrinA. However, Robo receptors are essential for RGC axon guidance (Plump et al., 2002; Thompson et al., 2009), and since we do not find defects in RGC innervation of the SC in Kir2.1-expressing RGC axons until they navigate to the correct TZ, it is unlikely that this is the case. An alternative explanation for this apparent neural type-specific requirement of activity for guidance molecule expression is that expression and/or function of some guidance molecules may rely on activity synchrony. In some developing neural circuits, spontaneous activity is initially nonsynchronous, meaning that neighboring neurons that eventually innervate adjacent targets do not exhibit simultaneous trains of activity. If activity patterns bear information instructive for axon guidance, neurons with asynchronous activity might misinterpret important guidance cues. Eventually, activity patterns become organized and synchronized, and in a system where this happens late in development such as the mouse visual system or the chick motor system, pathfinding could be uncoupled from electrical activity to prevent the stochastic nature of early asynchronous activity from causing a high level of heterogeneity of axon guidance fidelity. Thus, in systems with robust synchrony of activity at earlier stages, of which the thalamus may be an example, activity could play an essential role at earlier developmental stages.

\section{Spontaneous activity in topography and map formation}

In vitro studies suggested that during the establishment of retinocollicular topography spontaneous activity must be present for the correct functioning of EphA/ephrinA signaling (Nicol et al., 2007). However, blocking activity with tetrodotoxin (TTX) does not affect EphA transcription (Nicol et al., 2007), and we now show that activity is not required to modulate EphA/ephrinA signaling in vivo either. How can we reconcile the apparent discrepancy concerning the role of activity in the establishment of visual topography between past in vitro and our current in vivo results? First, there are significant differences between using TTX in culture and delivering Kir2.1 specifically in RGCs in vivo to block activity. TTX abolished spontaneous activity in the whole coculture, including the retinal explants and the SC slices. The use of Kir2.1, however, allows the blocking of spontaneous activity specifically in a restricted population of RGCs, leaving the rest of the retinal population and the SC unaffected. Second, the organotypic retinotectal cocultures used in the in vitro experiments corresponded to different retinal and collicular stages. E15 retinas were confronted to P6 SC slices, which makes it difficult to interpret the results since retinal axons at this early stage may not be ready to respond to signals from a more mature SC. Third, the ability to distinguish between the first (topography) and the second phase (remodeling) of the map maturation process using cocultures in vitro is very poor when compared with our in vivo approach, with which we can easily visualize and distinguish the retraction of the principal axon from axonal pruning and arborization in the correct TZ. Therefore, our in vivo results using a much more reliable approach demonstrate that activity is only required at later phases of development once retinal axons start to establish connections with other neurons in the SC.

Recent reports have shown that in newborn mice, retinal waves originate preferentially in the binocular region, the ventral-temporal retina, and propagate following a biased direction toward the dorsal-nasal retina (Ackman et al., 2012). This finding, although compatible with a role for retinal waves in topography, suggests an important function for spontaneous activity in eye-specific refinement. $\beta 2 \mathrm{KO}$ mice exhibit dramatically enlarged axonal arbors that fail to refine in the SC but exhibit a nearly normal topography (Dhande et al., 2011), and genetically modified mice with altered patterns of retinal activity exhibit defects in eye-specific refinement but an approximately normal rostrocaudal topography (Xu et al., 2011). Although none of these studies directly test a possible relationship between the expression of EphA/ephrinAs and spontaneous activity in the formation of topographic maps, they favor the idea of a prominent role for spontaneous activity in eye-specific segregation, which depends on fine-tuning of axonal terminals, rather than on topography.

In summary, our in vivo results clarify the long-standing debate over the precise roles of EphA/ephrinA signaling and spontaneous activity in neural circuit wiring, and finally confirm, at least in the motor and visual systems, the model initially proposed by Goodman and Shatz (1993) in which activityindependent mechanisms are sufficient to generate a coarse topographic map relying exclusively on molecular cues, whereas the fine-tuning of this map requires subsequent patterned activity.

\section{References}

Ackman JB, Burbridge TJ, Crair MC (2012) Retinal waves coordinate patterned activity throughout the developing visual system. Nature 490:219225. CrossRef Medline

Borodinsky LN, Spitzer NC (2007) Activity-dependent neurotransmitterreceptor matching at the neuromuscular junction. Proc Natl Acad Sci U S A 104:335-340. CrossRef Medline

Burrone J, O’Byrne M, Murthy VN (2002) Multiple forms of synaptic plasticity triggered by selective suppression of activity in individual neurons. Nature 420:414-418. CrossRef Medline

Cang J, Wang L, Stryker MP, Feldheim DA (2008) Roles of ephrin-as and structured activity in the development of functional maps in the superior colliculus. J Neurosci 28:11015-11023. CrossRef Medline

Carreres MI, Escalante A, Murillo B, Chauvin G, Gaspar P, Vegar C, Herrera 
E (2011) The transcription factor Foxd1 is required for the specification of the temporal retina. J Neurosci 31:5673-5681. CrossRef Medline

Dasen JS, De Camilli A, Wang B, Tucker PW, Jessell TM (2008) Hox repertoires for motor neuron diversity and connectivity gated by a single accessory factor, FoxP1. Cell 134:304-316. CrossRef Medline

Demarque M, Spitzer NC (2010) Activity-dependent expression of Lmx1b regulates specification of serotonergic neurons modulating swimming behavior. Neuron 67:321-334. CrossRef Medline

Dhande OS, Hua EW, Guh E, Yeh J, Bhatt S, Zhang Y, Ruthazer ES, Feller MB, Crair MC (2011) Development of single retinofugal axon arbors in normal and 2 knock-out mice. J Neurosci 31:3384-3399. CrossRef Medline

Erzurumlu RS, Kind PC (2001) Neural activity: sculptor of "barrels" in the neocortex. Trends Neurosci 24:589-595. CrossRef Medline

Feldheim DA, Nakamoto M, Osterfield M, Gale NW, DeChiara TM, Rohatgi R, Yancopoulos GD, Flanagan JG (2004) Loss-of-function analysis of EphA receptors in retinotectal mapping. J Neurosci 24:2542-2550. CrossRef Medline

Ferguson SC, McFarlane S (2002) GABA and development of the Xenopus optic projection. J Neurobiol 51:272-284. CrossRef Medline

Galli L, Maffei L (1988) Spontaneous impulse activity of rat retinal ganglion cells in prenatal life. Science 242:90-91. CrossRef Medline

Garcia-Frigola C, Carreres MI, Vegar C, Herrera E (2007) Gene delivery into mouse retinal ganglion cells by in utero electroporation. BMC Dev Biol 7:103. CrossRef Medline

Goodman CS, Shatz CJ (1993) Developmental mechanisms that generate precise patterns of neuronal connectivity. Cell 72 [Suppl]:77-98.

Goodman CS, Spitzer NC (1981) The mature electrical properties of identified neurones in grasshopper embryos. J Physiol 313:369-384. Medline

Hamburger V, Hamilton HL (1992) A series of normal stages in the development of the chick embryo. 1951. J Morphol 195:231-272.

Hanson MG, Landmesser LT (2004) Normal patterns of spontaneous activity are required for correct motor axon guidance and the expression of specific guidance molecules. Neuron 43:687-701. CrossRef Medline

Hanson MG, Landmesser LT (2006) Increasing the frequency of spontaneous rhythmic activity disrupts pool-specific axon fasciculation and pathfinding of embryonic spinal motoneurons. J Neurosci 26:12769-12780. CrossRef Medline

Hanson MG, Milner LD, Landmesser LT (2008) Spontaneous rhythmic activity in early chick spinal cord influences distinct motor axon pathfinding decisions. Brain Res Rev 57:77-85. CrossRef Medline

Herrera E, Brown L, Aruga J, Rachel RA, Dolen G, Mikoshiba K, Brown S, Mason CA (2003) Zic2 patterns binocular vision by specifying the uncrossed retinal projection. Cell 114:545-557. Medline

Kania A, Jessell TM (2003) Topographic motor projections in the limb imposed by LIM homeodomain protein regulation of ephrin-A:EphA interactions. Neuron 38:581-596. CrossRef Medline

Kao TJ, Law C, Kania A (2012) Eph and ephrin signaling: lessons learned from spinal motor neurons. Semin Cell Dev Biol 23:83-91. CrossRef Medline

Kastanenka KV, Landmesser LT (2010) In vivo activation of channelrhodopsin-2 reveals that normal patterns of spontaneous activity are required for motoneuron guidance and maintenance of guidance molecules. J Neurosci 30:10575-10585. CrossRef Medline

Katz LC, Shatz CJ (1996) Synaptic activity and the construction of cortical circuits. Science 274:1133-1138. CrossRef Medline

Kuwajima T, Sitko AA, Bhansali P, Jurgens C, Guido W, Mason C (2013) ClearT: a detergent- and solvent-free clearing method for neuronal and non-neuronal tissue. Development 140:1364-1368. CrossRef Medline

Luria V, Krawchuk D, Jessell TM, Laufer E, Kania A (2008) Specification of motor axon trajectory by Ephrin-B:EphB signaling: symmetrical control of axonal patterning in the developing limb. Neuron 60:1039-1053. CrossRef Medline

Maffei L, Galli-Resta L (1990) Correlation in the discharges of neighboring rat retinal ganglion cells during prenatal life. Proc Natl Acad Sci U S A 87:2861-2864. CrossRef Medline

McLaughlin T, Hindges R, O'Leary DD (2003) Regulation of axial patterning of the retina and its topographic mapping in the brain. Curr Opin Neurobiol 13:57-69. CrossRef Medline
Mire E, Mezzera C, Leyva-Díaz E, Paternain AV, Squarzoni P, Bluy L, Castillo-Paterna M, López MJ, Peregrín S, Tessier-Lavigne M, Garel S, Galcerán J, Lerma J, López-Bendito G (2012) Spontaneous activity regulates Robol transcription to mediate a switch in thalamocortical axon growth. Nat Neurosci 15:1134-1143. CrossRef Medline

Nakamura H, O'Leary DD (1989) Inaccuracies in initial growth and arborization of chick retinotectal axons followed by course corrections and axon remodeling to develop topographic order. J Neurosci 9:3776-3795. Medline

Nicol X, Voyatzis S, Muzerelle A, Narboux-Nême N, Südhof TC, Miles R, Gaspar P (2007) cAMP oscillations and retinal activity are permissive for ephrin signaling during the establishment of the retinotopic map. Nat Neurosci 10:340-347. CrossRef Medline

Nishiyama M, Hoshino A, Tsai L, Henley JR, Goshima Y, Tessier-Lavigne M, Poo MM, Hong K (2003) Cyclic AMP/GMP-dependent modulation of $\mathrm{Ca} 2+$ channels sets the polarity of nerve growth-cone turning. Nature 423:990-995. CrossRef Medline

O’Donovan MJ, Landmesser L (1987) The development of hindlimb motor activity studied in the isolated spinal cord of the chick embryo. J Neurosci 7:3256-3264. Medline

Pfeiffenberger C, Cutforth T, Woods G, Yamada J, Rentería RC, Copenhagen DR, Flanagan JG, Feldheim DA (2005) Ephrin-As and neural activity are required for eye-specific patterning during retinogeniculate mapping. Nat Neurosci 8:1022-1027. CrossRef Medline

Pfeiffenberger C, Yamada J, Feldheim DA (2006) Ephrin-As and patterned retinal activity act together in the development of topographic maps in the primary visual system. J Neurosci 26:12873-12884. CrossRef Medline

Plazas PV, Nicol X, Spitzer NC (2013) Activity-dependent competition regulates motor neuron axon pathfinding via PlexinA3. Proc Natl Acad Sci U S A 110:1524-1529. CrossRef Medline

Plump AS, Erskine L, Sabatier C, Brose K, Epstein CJ, Goodman CS, Mason CA, Tessier-Lavigne M (2002) Slit1 and Slit2 cooperate to prevent premature midline crossing of retinal axons in the mouse visual system. Neuron 33:219-232. CrossRef Medline

Reber M, Burrola P, Lemke G (2004) A relative signalling model for the formation of a topographic neural map. Nature 431:847-853. CrossRef Medline

Rousso DL, Gaber ZB, Wellik D, Morrisey EE, Novitch BG (2008) coordinated actions of the forkhead protein Foxp1 and Hox proteins in the columnar organization of spinal motor neurons. Neuron 59:226-240. CrossRef Medline

Simon DK, O'Leary DD (1992) Development of topographic order in the mammalian retinocollicular projection. J Neurosci 12:1212-1232. Medline

Spitzer NC (2006) Electrical activity in early neuronal development. Nature 444:707-712. CrossRef Medline

Stosiek C, Garaschuk O, Holthoff K, Konnerth A (2003) In vivo two-photon calcium imaging of neuronal networks. Proc Natl Acad Sci U S A 100: 7319-7324. CrossRef Medline

Thompson H, Andrews W, Parnavelas JG, Erskine L (2009) Robo2 is required for Slit-mediated intraretinal axon guidance. Dev Biol 335:418 426. CrossRef Medline

Tsuchida T, Ensini M, Morton SB, Baldassare M, Edlund T, Jessell TM, Pfaff SL (1994) Topographic organization of embryonic motor neurons defined by expression of LIM homeobox genes [see comments]. Cell 79: 957-970. CrossRef Medline

Xu HP, Furman M, Mineur YS, Chen H, King SL, Zenisek D, Zhou ZJ, Butts DA, Tian N, Picciotto MR, Crair MC (2011) An instructive role for patterned spontaneous retinal activity in mouse visual map development. Neuron 70:1115-1127. CrossRef Medline

Yamada A, Uesaka N, Hayano Y, Tabata T, Kano M, Yamamoto N (2010) Role of pre- and postsynaptic activity in thalamocortical axon branching. Proc Natl Acad Sci U S A 107:7562-7567. CrossRef Medline

Zhao Y, Araki S, Wu J, Teramoto T, Chang YF, Nakano M, Abdelfattah AS, Fujiwara M, Ishihara T, Nagai T, Campbell RE (2011) An expanded palette of genetically encoded $\mathrm{Ca}^{2+}$ indicators. Science 333:1888-1891. CrossRef Medline 